\title{
Efeitos das mudanças climáticas sobre a agropecuária de Minas Gerais: uma abordagem contemporânea
}

\section{Effects of climate change on agriculture in Minas Gerais: a contemporary approach}

Nilta Izabela Braga - Mestranda no Programa de Pós-Graduação em Desenvolvimento, Planejamento e Território da Universidade Federal de São João Del-Rei (PGDPLAT/ UFSJ).E-mail: niltaibraga@yahoo.com.br

Rosa Livia Gonçalves Montenegro - Doutora em Economia, pela Universidade Federal de Minas Gerais (UFMG). Professora da Universidade Federal de Juiz de Fora (UFJF). E-mail: rosa.livia@ufjf.br

\section{Resumo}

As mudanças climáticas são uma das maiores preocupações das sociedades contemporâneas e há evidências de que elas já estão provocando severos impactos negativos no mundo. O principal objetivo deste artigo é discutir os efeitos das mudanças climáticas projetadas para os próximos anos na produção agropecuária do estado de Minas Gerais. Para tanto, aplicou-se a metodologia de análise exploratória de dados espaciais (AEDE), com a proposta de identificar a concentração espacial das principais atividades do setor na região. Os resultados comparam trabalhos importantes na área, evidenciando os efeitos das mudanças climáticas na agropecuária mineira. Ademais, confirma-se que o estado de Minas Gerais será fortemente impactado pelos prejuízos causados nas atividades agropecuárias, caso não forem tomadas medidas urgentes de mitigação e adaptação às mudanças climáticas.

\section{Palavra-chave}

Mudanças climáticas. Agropecuária. Minas Gerais. Meio ambiente.

\begin{abstract}
Climate change is a major concern for contemporary societies and there is evidence that it is already causing severe negative impacts around the world. The main objective of this article is to discuss the effects of climate change projected for the coming years on agricultural production in the state of Minas Gerais. To this end, it is intended to contextualize the role of agriculture in the State, analyzing the spatial concentration of the main activities of the sector in the region and presenting results of important work regarding the impacts of climate change on agriculture in Minas Gerais. The results show that Minas Gerais will be strongly impacted by the losses caused in agricultural activities if urgent mitigation and adaptation measures are not taken.
\end{abstract}

\section{Keywords}

Climate change. Agriculture. Minas Gerais. Environment. 


\section{INTRODUÇÃO}

É latente a aceitação em âmbito internacional de que as mudanças climáticas já afetam o planeta e elevações de temperatura, ainda mais bruscas, provocarão uma série de efeitos prejudiciais às espécies e plantas nas diversas regiões do mundo. Conforme advertem Pellegrino, Assad e Marin (2007), há evidências de que ocorrerão mudanças climáticas globais, dado o aumento da concentração de gases de efeito estufa, como o gás carbônico $\left(\mathrm{CO}_{2}\right)$, o metano $\left(\mathrm{CH}_{4}\right)$ e o óxido nitroso $\left(\mathrm{N}_{2} \mathrm{O}\right)$, além do próprio vapor d'água $\left(\mathrm{H}_{2} \mathrm{O}\right)$. Algumas atividades têm mais responsabilidades na emissão desses gases, como é o caso da agropecuária, responsável por grande parte das emissões totais de gases de efeito estufa no Brasil.

De acordo com o relatório apresentado pelo Sistema de Estimativas de Emissões de Gases de Efeito Estufa (SEEG, 2019), do Observatório do Clima, o Brasil emitiu 1,939 bilhão de toneladas brutas de gases de efeito estufa, medidas em gás carbônico equivalente $\left(\mathrm{CO}_{2} \mathrm{e}\right)$ em 2018. Sendo que, 44\% destas emissões são provenientes das mudanças de uso da terra, sobretudo do desmatamento na Amazônia e no cerrado e $25 \%$ da agropecuária. Porém, trata-se de um setor que também sofrerá muito no futuro, com os impactos negativos das elevações na temperatura do ar. Conforme pontuado por Lima (2002), a agricultura é uma atividade que depende, diretamente, do clima e as alterações nesse componente podem ter sérios reflexos sociais e econômicos.

Neste contexto, surgem preocupações com a capacidade futura do planeta de suprir as demandas por alimentos para as gerações futuras. Assim, tornam-se relevantes as discussões sobre os impactos das mudanças climáticas na agropecuária de países e regiões que possuem, nesse setor, sua base econômica, que é o caso do Brasil e, mais especificamente, do estado de Minas Gerais. Trata-se de uma discussão notoriamente relevante, num período da política brasileira em que a defesa dos recursos naturais e da biodiversidade brasileira não é prioridade.

Portanto, o presente estudo promove a reflexão sobre os efeitos das mudanças climáticas na produção agropecuária de Minas Gerais. A partir do momento em que a atividade econômica é importante para o estado, destacase suas consequências na produção para o comércio e na produção para a autossubsistência.

O objetivo do trabalho é contribuir para a discussão dos efeitos das mudanças climáticas projetadas para os próximos anos, na produção agropecuária do estado de Minas Gerais. Para tanto, pretende-se apresentar uma discussão teórica sobre as principais considerações acerca da problemática referente à mudança climática, 
discutindo os conceitos de adaptação, vulnerabilidade e mitigação. Além disso, será contextualizado o papel da agropecuária no estado de Minas Gerais, em que será analisado a concentração espacial das principais atividades do setor no Estado e será apresentado os resultados de trabalhos importantes, no que se refere aos efeitos das mudanças climáticas na agropecuária mineira.

Este estudo, sobre o recorte territorial do estado de Minas Gerais, justificase pela sua agropecuária ser um dos mais importantes setores da economia, além de ser uma atividade altamente emissora de gases de efeito estufa e que mais precisará de medidas para se adaptar às mudanças climáticas. Trata-se, portanto, de uma atividade caracterizada pela produção intensiva de alimentos, por intermédio de técnicas que provocam sérios danos ao meio ambiente. É válido ressaltar a fragilidade dos pequenos produtores e produtores familiares que menos possuem condições de manter-se em suas atividades, se o cenário pessimista quanto ao futuro em relação às mudanças climáticas se confirmar. Isto posto, o debate acerca de ações de adaptação e de mitigação dos danos provocados por este setor torna-se cada vez mais relevante e iminente. Assim, a contribuição do presente debate é de investigar o estado de Minas Gerais, em relação aos efeitos que a agropecuária mineira provoca nas mudanças climáticas, e analisar os prejuízos que os cenários projetados podem ocasionar à economia mineira e ações que o estado tem empregado para mitigar os impactos climáticos.

Em resumo, este estudo divide-se, além desta introdução e das considerações finais, em mais quatro seções. A segunda seção apresenta algumas considerações gerais sobre mudanças climáticas e a percepção global quanto a mitigação de seus impactos na natureza. Já a terceira parte do estudo aborda as responsabilidades e desafios da agropecuária quanto às mudanças climáticas. A quarta seção contempla a metodologia utilizada para se chegar aos objetivos do estudo. Por fim, é tecida uma discussão sobre as consequências das mudanças climáticas na agropecuária de Minas Gerais.

\section{MUDANÇAS CLIMÁTICAS E SUA DINÂMICA GLOBAL}

Uma das grandes discussões do século XXI trata das questões relacionadas à mudança no clima e suas consequências para a humanidade, bem como para as demais espécies que habitam a Terra. $\mathrm{Na}$ definição do Painel Intergovernamental sobre Mudanças Climáticas (IPCC) ${ }^{1}$, as mudanças climáticas referem-se a

Entidade responsável pelos relatórios tidos como referência internacional sobre mudanças climáticas (BLANK, 2015). O IPCC foi criado pela Organização Meteorológica Mundial (OMM) juntamente com o Programa das Nações Unidas para o Meio Ambiente (PNUMA), em 1988. O objetivo principal do Painel é o de realizar análises sistemáticas sobre o conhecimento 
qualquer mudança do clima, ao longo do tempo, de ordem natural ou originadas da ação do homem (IPCC, 2007).

Apesar de, muitas vezes, a ciência ser desacreditada, principalmente por setores, entidades e indivíduos interessados em manter o atual padrão de produção altamente degradante ao meio ambiente, há evidências ${ }^{2}$ de autores como Behrenfeld et al. (2006), Pounds et al. (2006) e Malcolm e Markham (2000), em que comprovam que as mudanças climáticas continuarão a ocorrer num futuro próximo, provocando sérios danos e limitações à vida de várias espécies (BELLARD et al., 2012) .

Muitas destas evidências estão também relacionadas a observações, como o aumento da concentração de gases de efeito estufa; a diminuição do gelo no ártico, no desmoronamento de geleiras na Antártica e na redução das geleiras acumuladas no topo de montanhas como, por exemplo, a cordilheira do Himalaia; a elevação do nível dos oceanos; as mudanças nos regimes de chuvas; a desertificação; e o aumento da incidência de doenças (MIRANDA et al., 2018).

Os relatórios do IPCC alertam sobre a dinâmica das mudanças climáticas, baseando-se na tendência de aumento da temperatura média global do ar e dos oceanos, na intensificação do derretimento de neve e gelo e, consequentemente, na elevação do nível médio do mar (IPCC, 2007).

Para Martins et al. (2010), as ações antrópicas que interferem na mudança do clima podem ser um dos maiores desafios que a humanidade terá que aprender a lidar neste século. Conforme alerta o Relatório sobre Desenvolvimento Mundial de 2010: “[...] a mudança climática provocada pelos seres humanos está ocorrendo na escala de um século, dando pouco tempo para as sociedades e os ecossistemas se adaptarem ao ritmo rápido" (BANCO MUNDIAL, 2010, p. 4).

Conforme destaca o relatório do IPCC (2007), a ação do ser humano sobre o meio ambiente tem provocado o aumento da concentração de gases de efeito estufa, como o Dióxido de Carbono $\left(\mathrm{CO}_{2}\right)$, o Metano $\left(\mathrm{CH}_{4}\right)$, o Óxido Nitroso $\left(\mathrm{N}_{2} \mathrm{O}\right)$, o Hexafluoreto de Enxofre $\left(\mathrm{SF}_{6}\right)$, o Perfluormetano $\left(\mathrm{CF}_{4}\right)$, o Hidrofluorcarbono (HFC) e o Clorofluorcarbono (CFC) (ASSAD et al., 2004). Estes gases de efeito estufa são provenientes da queima de combustíveis fósseis

científico existente sobre as mudanças climáticas globais, seus impactos potenciais e as opções de mitigação e adaptação (GHINI et al., 2007).

2 O IPCC (2007) adverte sobre a existência de eventos extremos, como secas, enchentes, ondas de calor e de frio, furações e tempestades, causados pelas mudanças climáticas e que têm afetado diferentes partes do planeta e produzido enormes perdas econômicas e de vidas. Em pesquisa liderada pelo ecólogo J. Alan Pounds, da Reserva de Floresta Tropical de Altitude de Monteverde, na Costa Rica, os pesquisadores descobriram que mais de 70 espécies de sapos da América tropical já foram dizimadas por um fungo que se beneficia de temperaturas mais altas. Malcolm e Markham (2000) evidenciaram a relação entre o aquecimento global e o declínio da biodiversidade no Hemisfério Norte (BELLARD et al., 2012). 
em atividades industriais e transportes, bem como de mudanças de uso da terra, das atividades agrícolas e uso de combustíveis fósseis, da fertilização na agricultura e de processos industriais, dentre outros.

Desde seu quarto Relatório de Avaliação das Mudanças Climáticas, publicado em 2007, o IPCC atribui, com maior ênfase, o aquecimento global às atividades humanas (IPCC, 2007). A constatação foi possível, devido aos avanços científicos e metodológicos, desde o relatório anterior, que permitiram afirmar a influência do homem sobre o clima (BLANK, 2015).

Deste modo, em função do caráter antrópico das mudanças climáticas, as ciências sociais começam a olhar com mais atenção ao tema. Para Bernauer (2013), o caso de as mudanças climáticas serem causadas, em grande parte, pela humanidade e, em contrapartida, afetá-la diretamente, bem como aos animais, plantas e ecossistemas, fazem levantar questões que são de extrema importância para os cientistas, sejam eles vinculados às áreas sociais ou naturais. Destacamse, neste cenário, trabalhos de autores contemporâneos consagrados em teoria social, como Beck (2009) e Giddens (2015), que não apenas incorporaram as mudanças climáticas em seus estudos, como as trouxeram para o centro de sua elaboração teórica, conforme citam Fleury, Miguel e Tadei (2019).

A sociedade do risco, termo cunhado por Beck (2009) e Giddens (2015), seria eminentemente global, já que os riscos passaram a ser distribuídos democraticamente, não importando diferenças econômicas, sociais, geográficas ou temporais (BECK, 2009; FLEURY; MIGUEL; TADEI, 2019).

Giddens (2015), no que lhe concerne, enfatiza suas preocupações quanto ao comportamento da sociedade em relação às mudanças climáticas. Para o autor, a mudança climática ainda não é tangível no cotidiano das pessoas e seu caráter global dificulta ainda mais esta percepção. Isso implica numa dinâmica de ação contra os efeitos das mudanças climáticas quando estes já são visíveis (MARTINS et al., 2010). Logo, a breve discussão realizada apresentou ações que têm sido realizadas, no sentido da mitigação dos impactos de adaptação às mudanças no clima, e que também nortearão os objetivos do próximo item.

\subsection{ESTUDOS EMPÍRICOS SOBRE A VULNERABILIDADE E SUA RELAÇÃO COM AS MUDANÇAS CLIMÁTICAS}

É notória a importância dada pelos cientistas contemporâneos de se compreender os aspectos de vulnerabilidade em relação às mudanças climáticas, no intuito de propor ações que melhor combatam os seus impactos mais perversos. De acordo com o IPCC (2007) vulnerabilidade se refere ao grau de 
suscetibilidade ou incapacidade de um sistema para lidar com os efeitos adversos da mudança do clima, inclusive a variabilidade climática e os eventos extremos de tempo. Assim, para o IPCC (2007), vulnerabilidade seria em função de três aspectos principais: i) exposição do sistema, ou seja, quem ou o que estaria em risco; ii) sensibilidade do sistema, que se refere à intensidade dos choques que as pessoas ou sistemas podem sofrer; e, iii) a capacidade adaptativa do sistema, que seria a habilidade de se adaptar aos impactos.

Eakin e Luers (2006) atrelam o conceito de vulnerabilidade, de acordo com a distribuição desigual de recursos e de acesso, ao controle que indivíduos conseguem fazer sobre escolhas e oportunidades e a padrões históricos de marginalização e dominação social. Assim, é preciso conhecer as condições de exposição aos riscos das mudanças climáticas, para melhor compreender a capacidade de adaptação de um determinado sistema. Para Martins et al. (2010), é preciso desenvolver procedimentos para avaliar a vulnerabilidade e o seu comportamento no tempo, dado as ações intencionais, no intuito de assegurar o adequado entendimento dos impactos das mudanças climáticas.

Neste contexto, alguns estudos como os de Beg et al. (2002) e Beck (2009) têm relatado a condição de vulnerabilidade às mudanças climáticas a que estão expostos os países não desenvolvidos, como o Brasil, que apresenta, por exemplo, histórico de dificuldades em lidar com desastres naturais, como secas, enchentes e deslizamentos de encostas (PELLEGRINO; ASSAD; MARIN, 2007).

Conforme adverte o Relatório sobre o Desenvolvimento Mundial (BANCO MUNDIAL, 2010), os países em desenvolvimento são mais expostos e menos resilientes aos perigos climáticos e, provavelmente, arcarão com a maior parte dos custos pelos danos — cerca de 75\%-80\%. Esses países são, geralmente, muito dependentes econômica e socialmente de setores primários: "Os países em desenvolvimento são particularmente dependentes dos serviços de ecossistema e de capital natural para a produção nos setores sensíveis ao clima" (BANCO MUNDIAL, 2010, p. 5-6).

Assim, a questão da vulnerabilidade se agrava, de acordo com seus impactos sobre a agricultura dos países pobres, de maneira geral, fortemente dependentes da atividade agrícola, seja ela de subsistência ou considerada como a base da economia nacional (PELLEGRINO; ASSAD; MARIN, 2007). Desta forma, entende-se que a agricultura seja um setor diretamente associado às causas das mudanças climáticas de origem antrópica, sendo, o que mais sofre com os efeitos destas mudanças. Compreender a dinâmica das mudanças é o objetivo da próxima seção. 


\section{AGROPECUÁRIA BRASILEIRA: RESPONSABILIDADES E DESAFIOS QUANTO ÀS MUDANÇAS CLIMÁTICAS}

O setor agropecuário é sempre citado entre os principais setores responsáveis pelas mudanças climáticas no mundo, em consequência das altas taxas de emissão de gases de efeito estufa como: o dióxido de carbônico, o óxido nitroso e o metano. O IPCC (2007) estima que 23\% das emissões mundiais de gases de efeito estufa de origem antropogênica, entre 2007 e 2016, derivam da agricultura e da silvicultura. Estes níveis de emissão se elevam, dependendo das características produtivas principais de cada país. No Brasil, país essencialmente agroexportador, as atividades de agropecuária e mudanças no uso da terra, responderam por $69 \%$ das emissões de gases de efeito estufa no país, em 2018, de acordo com dados do SEEG (2019).

Trata-se de uma situação delicada, pois as projeções indicam crescimento populacional nas próximas décadas e consequente elevação na demanda por alimentos. Além disso, de acordo com a FAO (2012), 795 milhões de pessoas estão desnutridas, ou seja, uma em cada nove pessoas não tem comida suficiente para levar uma vida ativa e saudável no mundo. A questão seria como aumentar a produção sem prejudicar ainda mais o meio ambiente, sem acelerar a degradação dos solos, dos recursos hídricos, das florestas e a elevação na temperatura, e que não comprometa as condições de vida na terra. Enfim, esta é uma condição que desafia a agropecuária mundial e, principalmente, a brasileira.

Para produzir e alimentar uma população crescente, ao mesmo tempo em que se tem a obrigação de reduzir suas emissões, é necessário a exigência de novas práticas agrícolas e o conhecimento de que as ações humanas desencadeiam alterações no clima e no ambiente (MIRANDA et al., 2018). Para a Embrapa (2018), seria urgente a necessidade de uma agricultura de baixo carbono e do desenvolvimento de tecnologias, para mitigar os efeitos negativos do clima nos cultivos e nas criações.

Pellegrino, Assad e Marin (2007) destacam que o Brasil precisa resolver o problema da expansão da fronteira agrícola, com seu indiscriminado apelo à derrubada e às queimadas. Embora seja usado o argumento de que são necessárias novas áreas para a produção de alimentos, a abertura dessas áreas causa vários impactos ambientais negativos.

Neste sentido, o país precisa buscar formas de produzir em que também reduzam os impactos ambientais, e em que se utilize ferramentas de mitigação e adaptação às mudanças climáticas, na busca do desenvolvimento sustentável e 
responsável. Assad et al. (2004) salientam que vários estudos têm se preocupado com esta questão e têm procurado meios de adaptação e de busca por novos sistemas de produção, visando reduzir os impactos estimados nos cenários de mudanças climáticas projetadas. De acordo com a percepção dos consumidores norte-americanos, Howe et al. (2016) evidenciaram que 70\% dos norte-americanos acreditam que o aquecimento global esteja realmente acontecendo, mas apenas $40 \%$ deles temem que a mudança do clima os prejudique pessoalmente.

No setor agropecuário, alguns estudos (ANDRADE; SILVA; SOUZA, 2014; MARTINS et al., 2010; PIRES et al., 2014) também identificaram que os agricultores possuem a percepção de que as mudanças no clima acontecem e sobre a responsabilidade da agropecuária neste processo, mas, geralmente, poucas ações efetivas têm sido realizadas para reverter este quadro. Trabalhos que versam sobre estudos de casos, evidenciaram que a grande maioria dos produtores rurais, de diferentes regiões brasileiras, têm consciência das mudanças climáticas em curso (PIRES et al., 2014). Esta percepção é geralmente associada às alterações nos padrões de precipitação, elevação da temperatura e intensificação de eventos extremos como secas, chuvas intensas e geadas (PIRES et al., 2014). Porém, conforme observado no estudo de Pires et al. (2014), apenas 24\% dos agricultores têm alterado as suas práticas agrícolas para lidar com os impactos das mudanças climáticas.

Dessa forma, além de descobrir meios de mitigação e adaptação aos impactos das mudanças no clima, é necessário levar este conhecimento ao produtor. Para Miranda et al. (2018), as informações técnicas relacionadas aos impactos das mudanças climáticas e medidas de mitigação são essenciais para que alcancem os produtores rurais, principalmente pequenos e médios, em que possuem menos acesso às informações. Pires et al. (2014) acrescentam que conhecer a percepção ambiental dos produtores rurais é imprescindível e, portanto, possibilita o desenvolvimento de estratégias de ação quanto aos impactos das mudanças climáticas.

Em suma, entende-se que a humanidade precisa levar em consideração as suas responsabilidades quanto às mudanças climáticas e buscar soluções que propiciem a continuidade da vida na terra. Setores como a agropecuária, que contribuem com estas mudanças e sofrerá com seus efeitos danosos, precisam propor ações de mitigação e adaptação que estejam ao alcance de todos os produtores, independentemente do tamanho de suas propriedades. 


\section{METODOLOGIA DA PESQUISA}

Para este estudo, foi delineado um panorama da agropecuária de Minas Gerais com base nos dados do Censo Agropecuário 2017 (IBGE, 2019), para introduzir o contexto atual deste setor no Estado. Com a mesma base de dados, realizou-se uma análise espacial da concentração das lavouras permanente e temporária, bem como da pecuária bovina em Minas Gerais, que permitiu ampliar a discussão em torno das diferenças regionais dentro do território mineiro. Segundo Gonçalves (2007, p. 11), “a análise exploratória de dados espaciais é útil para descrever distribuições espaciais, revelando padrões espaciais (clusters espaciais), regimes espaciais ou outras formas de instabilidade espacial (nãoestacionariedade) e observações atípicas (outliers)".

O Censo Agropecuário 2017 (IBGE, 2019) disponibiliza informações para o Brasil, para os Estados nacionais, bem como para a maioria dos municípios, sobre a lavoura permanente, a lavoura temporária e a pecuária. Quanto à lavoura permanente, estão disponíveis informações sobre:

- Área colhida, número de estabelecimentos, número de pés plantados e valor da produção.

Já para a lavoura temporária têm-se os seguintes dados:

- Área colhida, número de estabelecimentos e valor da produção.

Por fim, para a pecuária bovina encontra-se informações quanto a:

- Efetivo do rebanho, número de estabelecimentos, efetivo do rebanho de vacas ordenhadas, estabelecimentos que produziram leite, quantidade de leite de vaca produzida e valor da produção de leite de vaca.

No presente estudo, são utilizadas as informações sobre o valor da produção para a análise espacial das lavouras permanentes e temporárias de Minas Gerais. Ademais, para a pecuária bovina, os dados utilizados para a análise espacial no Estado foram, também, o valor da produção de leite de vaca.

É importante ressaltar, que a escolha da pecuária bovina se deve a sua relevância na economia mineira. Assim, os estudos analisados buscaram verificar de que maneira um aumento de temperatura afetaria o ciclo de uma determinada planta, no intuito de apontar em quais situações a planta atingirá sua produção máxima, sem sofrer perdas (ASSAD et al., 2004). Destaca-se que estes estudos, relacionados ao zoneamento agrícola de risco climático, em geral, desconsideram evoluções tecnológicas ou qualquer adaptação fisiológica das plantas que possam ocorrer. 


\section{RESULTADOS: A AGROPECUÁRIA MINEIRA E OS EFEITOS PROVOCADOS PELAS MUDANÇAS CLIMÁTICAS}

De acordo com dados do Censo Agropecuário do ano de 2017 (IBGE, 2019), Minas Gerais conta com uma população de cerca de 19,6 milhões de pessoas e uma área de 586,5 mil km². Quanto à economia do Estado, o setor que se destaca, em relação à representatividade no PIB mineiro, é o setor de serviços, com quase 70\% de contribuição no PIB total de Minas Gerais (IBGE, 2019).

Contudo, o setor agropecuário também é forte no território mineiro, representando 6,1\% do PIB estadual, sendo o segundo maior Estado em valor de produção agropecuária do país. O valor de produção supracitado totaliza quase $\mathrm{R} \$ 60$ bilhões, dos quais 60\% está atrelado à produção vegetal e 40\% à produção animal, ficando atrás apenas do estado de São Paulo (IBGE, 2019).

O Censo Agropecuário assemelha-se a um retrato da agropecuária do País e dos Estados, com uma série de informações relevantes sobre o setor. Com base no Censo Agropecuário, o presente item apresentará um resumo das principais informações acerca da agropecuária no estado de Minas Gerais, para debater sobre a produção agropecuária mineira e suas implicações em função das mudanças climáticas em curso e do cenário mais pessimista para o futuro.

O Censo também mostrou que Minas Gerais deteve o destaque no valor de produção das lavouras permanentes, uma vez que concentra a produção nacional de café arábica; o maior valor de produção animal, pela elevada produção de leite de vaca; e o maior valor de produção de carvão vegetal, com a maior área de florestas plantadas. O estado se destaca, ainda, pelo segundo lugar no valor de vendas de suínos, atrás apenas do Rio Grande do Sul e, pelo segundo lugar, no valor de produção de laranja e da horticultura, depois de São Paulo; além de ser o maior produtor de batata, alho, morango e cenoura do país.

Em Minas Gerais, assim como acontece no Brasil, a maior parte dos estabelecimentos rurais (46,4\%) possui tamanho entre 10 e 100 hectares. Quanto à utilização das terras, a maior quantidade de hectares é usada para pastagens, seguido pelas matas/florestas e, em terceiro, para lavouras. Em relação às técnicas de cultivo, 43\% dos estabelecimentos rurais declararam não utilizar qualquer tipo de adubação e 70\% dos estabelecimentos não utilizam agrotóxicos.

Contudo, o Censo Agropecuário do ano de 2017 revelou que, na comparação com o Censo Agropecuário do ano de 2006, houve um aumento de 60,6\% no número de estabelecimentos rurais que utilizam agrotóxicos, em Minas Gerais. Trata-se de um elevado aumento, ainda que Minas Gerais mantenha o percentual de estabelecimentos rurais que usam agrotóxicos, de $27,4 \%$, abaixo dos $33,1 \%$ 
observados no Brasil (IBGE, 2019). Vale destacar, conforme lembram Martins et al. (2010), que o Brasil é o maior consumidor de agrotóxicos do mundo e que este comportamento reflete, diretamente, na magnitude da emissão de gases de efeito estufa (GEE).

O uso indiscriminado ${ }^{3}$ destes produtos e sua relação com as mudanças climáticas são aceitos por grande parte dos agricultores, principalmente entre os pequenos produtores. Alguns estudos têm mostrado que os agricultores, em sua grande maioria, têm a percepção de que o uso de agrotóxicos é uma das principais causas da mudança climática (MARTINS et al., 2010). Isso pode representar um ponto forte a ser utilizado nas ações de adaptação e mitigação em relação aos efeitos das mudanças no clima, ao se utilizar o conhecimento dos produtores quanto às implicações do uso de agrotóxicos na mudança climática, buscando meios de adaptação e novos sistemas de produção, visando reduzir os impactos estimados nos cenários de mudanças climáticas projetadas (ASSAD et al., 2004).

No sistema de preparo do solo, $14 \%$ dos estabelecimentos rurais utilizam o plantio direto na palha, $41 \%$ utilizam o cultivo convencional e $46 \%$ utilizam o cultivo mínimo. Outro dado relevante é que $84 \%$ dos estabelecimentos rurais de Minas obtiveram financiamento, cujas finalidades se destacam em investimento e custeio, atendendo a $86 \%$ dos estabelecimentos rurais. A maior parte destes recursos vem do Governo Federal, principalmente por meio do Programa Nacional de Fortalecimento da Agricultura Familiar (PRONAF).

Outro dado que chama atenção é o fato de $70 \%$ dos estabelecimentos rurais do Estado declararem não receber assistência técnica alguma, o que pode ser uma grave deficiência no contexto da adaptação às mudanças climáticas, pois será necessário auxiliar os produtores na utilização de mecanismos de mitigação e adaptação à nova realidade (PIRES et al., 2014). A assistência técnica possui papel relevante na disponibilização de informações técnicas quanto aos impactos das mudanças climáticas e quanto às medidas de mitigação aos produtores rurais. Tal assistência é essencial que ocorra, principalmente devido às dificuldades de acesso à informação que muitos pequenos produtores ainda enfrentam (MIRANDA et al., 2018).

Os efeitos da contaminação humana por agrotóxicos ocorrem pelas vias ocupacional, ambiental e alimentar. Os efeitos ocupacionais configuram-se pela contaminação dos trabalhadores que manipulam os agrotóxicos, isto é, pela mistura e/ou diluição, pulverização, descarte de resíduos e embalagens contaminadas, manipulação do produto contaminado. Os efeitos ambientais caracterizam-se pela dispersão ou distribuição dos agrotóxicos no ambiente (a contaminação). Os impactos negativos pelo uso indiscriminado de agrotóxicos podem ser variados, como por exemplo: pela migração de resíduos de agrotóxicos para lençóis freáticos; a contaminação atmosférica, resultante da dispersão de partículas durante a pulverização ou de manipulação de produtos finamente granulados e evaporação de produtos mal estocados; e a contaminação dos solos. Por fim, pela via alimentar, os efeitos decorrem pela ingestão de produtos contaminados (VINHA et al., 2011). 
A Fundação João Pinheiro (2019) observa, com base nos dados do Censo Agropecuário do ano de 2017, que há uma concentração do setor agropecuário nas regiões: central, sul, oeste e noroeste do estado de Minas Gerais, que pode ser observada nas figuras a seguir (Figuras 1 a 3). As três culturas que se destacam na lavoura temporária do estado são: a soja, o milho e a cana-de-açúcar, tanto em área colhida quanto em valor da produção.

Percebe-se que, apesar da concentração da produção em algumas regiões de Minas Gerais (Figura 1), ocorre a presença de lavouras temporárias em quase todos os municípios mineiros. Assim, a inaptidão destas áreas para a produção, devido às mudanças climáticas, pode provocar uma desestruturação econômica e social nestes municípios, que precisarão buscar alternativas de adaptação e mitigação destes efeitos. A produção de soja em Minas Gerais já estará comprometida frente a um aumento de $1^{\circ} \mathrm{C}$ na temperatura e seria impraticável se ocorrer um aumento de $5,8^{\circ} \mathrm{C}$ (ASSAD et al., 2004).

Figura 1 - Concentração espacial da lavoura temporária de Minas Gerais por valor da produção em (X1000) reais

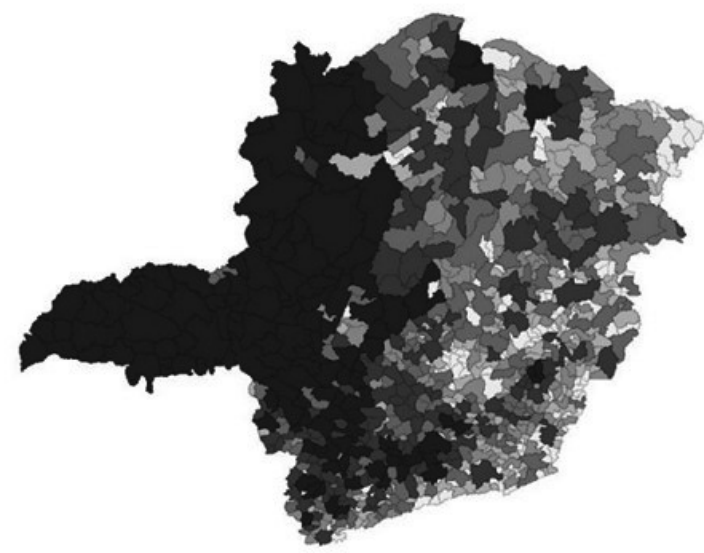

Legenda:

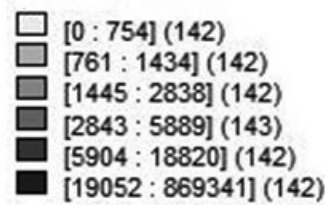

Fonte: elaboração própria no software Geoda, com dados do Censo Agropecuário 2017 (IBGE, 2019).

Já em relação à lavoura permanente de Minas Gerais, as três maiores culturas em área colhida e, também, em valor da produção são: o café arábica, a banana e a laranja. A Figura 2 apresenta a concentração espacial da lavoura permanente de Minas Gerais, em relação ao valor da produção. Nota-se, por esta análise, uma concentração de lavouras permanentes no oeste e sul de Minas, com alguns municípios relevantes em tamanho da área plantada e o valor da produção no norte e sudeste do estado. 
Ademais, é possível notar a presença de lavouras permanentes em quase todos os municípios do Estado e inferir sua importância na economia local. Assad et al. (2004) advertem que o aumento de $1^{\circ} \mathrm{C}$ na temperatura tornaria inaptos algumas partes do norte e leste do Estado para o cultivo do café e diante de um aumento de $5,8^{\circ} \mathrm{C}$ a cafeicultura não mais existiria em Minas Gerais ${ }^{4}$, sendo que a pecuária em Minas Gerais é responsável por quase 49\% dos valores gerados pelo agronegócio no estado.

Figura 2 - Concentração espacial da lavoura permanente de Minas Gerais por área colhida em hectares e valor da produção em (X1000) reais

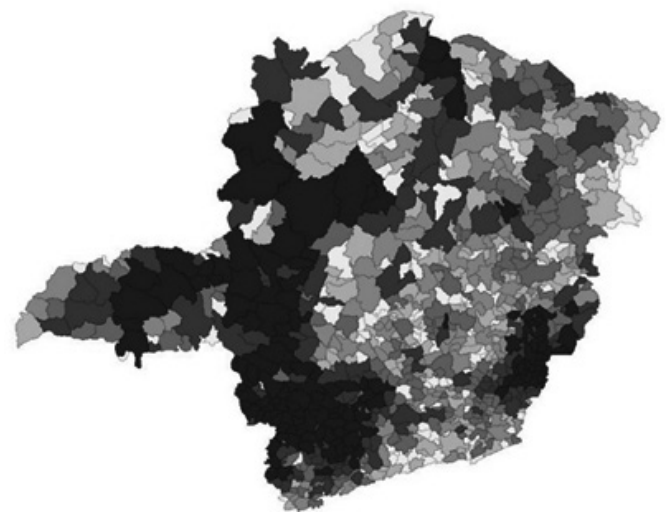

\section{Legenda:}

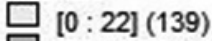

$\square[23: 144](145)$

$\square[145: 666](142)$

$\square[669: 3907](143)$

$\square[3923: 23706](142)$

$\square[23999: 449660](142)$

Fonte: elaboração própria no software Geoda, com dados do Censo Agropecuário 2017 (IBGE, 2019).

No setor da pecuária, Minas Gerais possui forte potencial na criação de gado leiteiro. Os bovinos se destacam tanto na quantidade produzida quanto no maior volume de produção no estado (Figura 3). A presença de pastagens em diversos biomas do Estado demonstra a necessidade de cuidados pelos pecuaristas quanto às práticas de manejo, no sentido de aliviar a degradação das pastagens e reduzir a emissão de gases do efeito estufa. Paulino e Teixeira (2010) advertem que é preciso um manejo adequado das pastagens para combater o aumento do efeito estufa, em favor do sequestro de carbono. Ademais, os autores ressaltam que a degradação da pastagem reduz a produtividade e gera perda de matéria orgânica do solo, além de aumentar a emissão de gás carbônico $\left(\mathrm{CO}_{2}\right)$ na atmosfera, em consequência da redução de sequestro de carbono na pastagem.

4 Para a região Sudeste, especificamente, "ainda que a chuva tendesse a aumentar no futuro, as elevadas temperaturas do ar poderiam, de alguma forma, comprometer a disponibilidade de água para agricultura, consumo ou geração de energia, devido a um acréscimo previsto na evaporação ou evapotranspiração. As vazões também tendem a aumentar como consequência do aumento de chuvas e das mudanças de uso da terra na região" (MARENGO; VALVERDE, 2007, p. 23). 
Com base no breve panorama, é possível avançar na discussão acerca das responsabilidades do setor em relação às mudanças climáticas, bem como estabelecer um vínculo com outros estudos que retratam as implicações destas mudanças na atividade agropecuária do Estado, caso algumas projeções se realizarem, de fato. Conforme já destacado, a agropecuária é um dos setores que mais contribui com a emissão de gases de efeito estufa e uma das atividades que mais sofrerá com os impactos das mudanças no clima.

Figura 3 - Concentração espacial da pecuária bovina em Minas Gerais em quantidade de leite de vaca produzida em (X1000) litros e valor da produção de leite de vaca em (X1000) reais

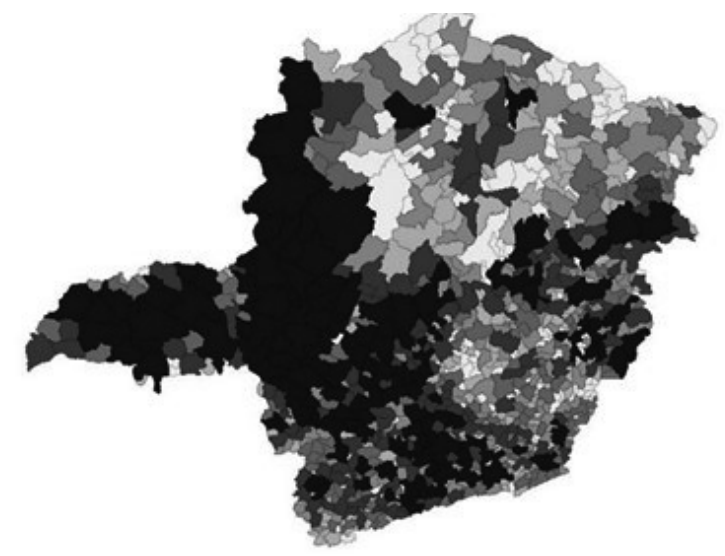

\section{Legenda:}

$\square[0: 1695](142)$

[1714: 3210] (142)

[3240: 5255] (142)

[5271 : 8632] (143)

[8687: 16490] (142)

[16568: 222777] (142)

Fonte: elaboração própria no software Geoda, com dados do Censo Agropecuário 2017 (IBGE, 2019).

De acordo com o observatório do clima, o setor agropecuário e as mudanças no uso da terra em Minas Gerais são responsáveis por uma participação relevante das emissões totais de gases de efeito estufa no Brasil (Figura 4). Somente nestas duas atividades, o estado é responsável por mais de $9 \%$ das emissões totais brasileiras de dióxido de carbono e de metano e de mais de 3\% das emissões totais nacionais de dióxido de carbono equivalente.

Para Van Vuuren et al. (2011), nos aspectos dos cenários ambientais, são considerados vias desenvolvidas chamadas de "Vias de concentração representativas", ou em inglês, RCPs. Elas desempenham um papel importante no fornecimento de informações para experimentos de modelos climáticos prospectivos, incluindo as projeções decadais e de longo prazo das mudanças climáticas. Os RCPs também fornecem um importante ponto de referência para novas pesquisas dentro da comunidade de modelagem de avaliação integrada 
(IAM), padronizando um conjunto comum de condições para o ano 2100 e explorando caminhos e políticas alternativas que poderiam produzir esses resultados. Logo, os RCPs, como um conjunto, contêm informações relevantes para execuções de modelos climáticos.

Os resultados apresentados revelam que a agropecuária de Minas Gerais tem causado sérios impactos nas mudanças climáticas, representando uma atividade que emite altas taxas de gases de efeito estufa. Contudo, se ações não forem tomadas a curto e médio prazo, o setor sofrerá fortes impactos negativos nos próximos anos, gerando altos prejuízos ao Estado e, portanto, ao País. Diversos autores e entidades (ASSAD et al., 2004; EMBRAPA, 2018; PELEGRINO et al., 2007) têm se dedicado a este assunto, avaliando e discutindo os impactos que as mudanças climáticas projetadas para os próximos anos podem provocar na agropecuária em geral e, em particular, em Minas Gerais.

Figura 4 - Percentual de emissões da agropecuária e mudanças no uso da terra no estado de Minas Gerais, em relação ao total nacional em 2018

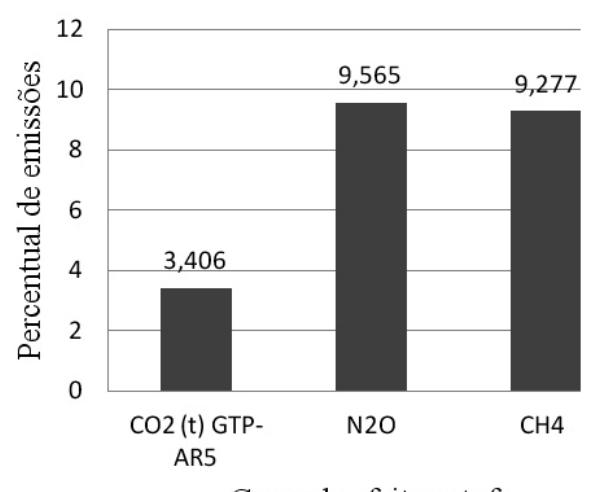

Gases de efeito estufa

Fonte: elaboração própria com base em dados da SEEG (2019).

De acordo com a Embrapa (2018), a soja é a cultura que sofrerá mais com a elevação da temperatura no Brasil. A cultura supracitada é o principal produto agrícola exportado pelo país, e pode apresentar, já no ano de 2020, uma perda de $\mathrm{R} \$ 3,9$ bilhões a $\mathrm{R} \$ 4,3$ bilhões, promovida por uma redução de área de baixo risco ao cultivo, oscilando entre 21,62\% a 23,59\% (EMBRAPA, 2018).

Assad et al. (2004) relatam que o Brasil tinha, até o ano do estudo - 2007, uma área favorável, com baixo risco, para o plantio de soja de 3,4 milhões de quilômetros quadrados, conforme indicações do zoneamento para esta cultura. Do mesmo modo, os autores ressaltam que o aumento de $1^{\circ} \mathrm{C}$ na temperatura global já comprometeria bastante esta produção (ASSAD et al., 2004). 
Nesse âmbito, Marego e Valverde (2007) alertam para as mudanças no uso da terra, que também têm afetado, sensivelmente, o clima na América do Sul. Para os autores, desde a década de 1990, estudos têm sido desenvolvidos simulando os efeitos no clima regional, associado ao desmatamento da Amazônia. As experiências assumem um desmatamento total na região, ou seja, toda a floresta é substituída por pastagem.

As projeções descritas deixam o Estado em alerta e na busca por implementar ações de mitigação e adaptação às mudanças climáticas. O Plano de Energia e Mudanças Climáticas do Estado de Minas Gerais (PEMC) (FEAM, 2015) salienta a estimativa de que, desde 2008, eventos climáticos extremos, como chuvas intensas e secas prolongadas, tenham custado 12,8 bilhões de reais ao estado. Caso não forem tomadas rápidas atitudes, os custos dos impactos para a economia mineira, decorrente das mudanças climáticas, podem alcançar $\mathrm{R} \$ 450$ bilhões até 2050. Para o PEMC, se as metas federais forem aplicadas ao contexto de Minas Gerais, haverá uma mitigação de GEE na ordem de 7 a 9\%, levandose em conta os Planos Setoriais de Mitigação e Adaptação nacionais que servem para o atendimento do compromisso voluntário firmado pelo Brasil em 2009, na Convenção do Clima, em Copenhague.

$\mathrm{Na}$ ocasião, o país se comprometeu a reduzir as emissões de gases de efeito estufa (GEE) na ordem de 36,1\% a 38,9\%, até este ano de 2020. Ainda em 2009, o País sancionou a Política Nacional de Mudança do Clima, transformando as metas firmadas em lei e criando instrumentos para sua consecução. De acordo com o Plano Nacional de Adaptação à Mudança do Clima (PNA), lançado no ano de 2016, o Brasil envolve-se de maneira decisiva na identificação, nas análises da vulnerabilidade e possíveis impactos por 11 temas de interesse nacional, identificados como suscetíveis às mudanças do clima, são eles: agricultura, recursos hídricos, segurança alimentar e nutricional, biodiversidade, cidades, gestão de risco aos desastres, indústria e mineração, infraestrutura, povos e populações vulneráveis, saúde e zonas costeiras (MMA, 2015).

Paralelamente ao PNA, a posição brasileira frente ao Acordo de Paris, no qual o Brasil assumiu o compromisso de reduzir suas emissões, merece destaque. Em outras palavras, o Brasil sinaliza um compromisso audacioso na redução de emissões absolutas e o de zerar o desmatamento ilegal, em 2030 (EULER, 2016). Logo, o país não pode ignorar os compromissos assumidos perante o Acordo, pois, além dos impactos financeiros gigantescos, a influência brasileira no aspecto ambiental global é tão imensa quanto a sua biodiversidade.

Em resumo, é importante avaliar como estas ações têm sido desenvolvidas e sua efetividade quanto aos objetivos propostos. Atualmente, o momento 
político do país não tem privilegiado o campo de ações relacionado à questão das mudanças climáticas e dos grandes desafios globais quanto ao uso consciente e sustentável dos recursos naturais. As primeiras ações do Governo Federal atual, quanto às políticas de preservação do meio ambiente, podem ter reflexos catastróficos ainda a curto prazo.

Entre estas ações, destaca-se o enfraquecimento do Ministério do Meio Ambiente, a ameaça aos povos e reservas indígenas e a liberação de agrotóxicos (FEARNSIDE, 2019). Contudo, mesmo no contexto políticonacional problemático, é possível destacar algumas iniciativas que têm logrado êxito na busca pelo desenvolvimento sustentável, que podem ser entendidas como o manejo e a conservação da base de recursos naturais e a orientação das mudanças tecnológicas, de forma a assegurar o alcance e a satisfação contínua das necessidades humanas do presente e das futuras gerações (FAO, 2012).

\section{CONSIDERAÇÕES FINAIS}

A partir das análises destacadas neste estudo, comprovou-se que os efeitos das mudanças climáticas podem provocar severos impactos negativos na agropecuária, especificamente no estado de Minas Gerais, causando danos econômicos, sociais e ambientais em todas as regiões de Minas, mas sobretudo na região Norte, dado sua dependência econômica do setor agrícola, vulnerabilidade e dificuldade de adaptação ao cenário futuro abordado no presente estudo.

Nas atividades agropecuárias, uma boa solução a médio e longo prazo seria a busca de instrumentos para reduzir as emissões de gases de efeito estufa e investimentos em ciência e tecnologia, com o objetivo de auxiliar o setor a produzir eficientemente, de forma sustentável, e respeitando o meio ambiente. Destaca-se, neste contexto, a oportunidade do setor agropecuário de evitar e diminuir as emissões de gases de efeito estufa ao se comprometer em não desmatar e reduzir as queimadas em áreas de preservação, o que seria um avanço. Ademais, também encorajar o reflorestamento, como medida de fortalecimento de sumidouros naturais.

Outro ponto de destaque é o uso indiscriminado de agrotóxicos no Brasil, que se intensificou a partir dos anos noventa e tornou o país um dos maiores consumidores de agrotóxicos no mundo. Observa-se que sua utilização é ampla em culturas muito representativas no Estado de Minas Gerais como a soja, o milho e a cana-de-açúcar. Enquanto a tendência mundial é de estabilização ou diminuição do uso destes produtos, no Brasil a liberação de vários agrotóxicos pelo governo atual revela uma despreocupação acentuada quanto aos efeitos 
destes ao meio ambiente e à saúde humana. Era de se esperar um comportamento oposto, principalmente por uma vasta coletânea de estudos que comprovam a relação entre o uso de agrotóxicos e a elevação nas emissões de gases de efeito estufa, causa direta das mudanças climáticas, ou seja, é necessário o crescimento de atividades de controle e prevenção ao uso irresponsável de agrotóxicos.

A agropecuária tem participação relevante na economia de Minas Gerais, além de seu papel socioeconômico, uma vez que a maioria dos estabelecimentos rurais são representados por pequenos produtores, que dependem da produção para seu sustento. Assim, é preocupante os cenários futuros que alertam que boa parte das culturas estabelecidas em Minas Gerais estão em risco se as mudanças climáticas se confirmarem e se nada for feito para mitigar seus efeitos. Em geral, é necessário a conscientização de que a agricultura e a pecuária em Minas Gerais estão correndo risco num futuro não distante em decorrência do aquecimento global e que medidas mais expressivas no âmbito das mudanças climáticas devem ser implementadas com urgência.

É importante considerar o papel das políticas públicas de mitigação e adaptação às mudanças climáticas. Minas Gerais conta com um plano de diretrizes para os mais diversos setores econômicos. Sugere-se, para fins de pesquisas futuras, uma avaliação aprofundada dos resultados de políticas públicas no âmbito das mudanças climáticas em vigor no estado, principalmente no que refere ao alcance das metas de redução na emissão de gases de efeito estufa a que o Brasil se comprometeu, já para este ano de 2020, frente ao Acordo de Copenhague, em 2009. Ainda que a política atual do país não esteja, aparentemente, comprometida com a questão, é importante que a Ciência e a Tecnologia no País continuem buscando alternativas para os cenários futuros de elevação da temperatura do ar, e que contribuam com a preservação das espécies e plantas de seu ecossistema.

Por fim, as alternativas propostas promovem a sensação de que é possível contornar os grandes desafios impostos pelas mudanças climáticas. Especificamente, proporciona ao estado Minas Gerais condições para que seja referência na produção agropecuária, com enfoque na sustentabilidade e no desenvolvimento socioeconômico e ambiental.

\section{REFERÊNCIAS}

ANDRADE, A. J. P.; SILVA, N. M.; SOUZA, C. R. As percepções sobre as variações e mudanças climáticas e as estratégias de adaptação dos agricultores familiares do Seridó potiguar. Desenvolvimento e Meio Ambiente, Curitiba, v. 31, p. 77-96, 2014. 
ASSAD, E. D. et al. Impacto das mudanças climáticas no zoneamento agroclimático do café no Brasil. Pesquisa Agropecuária Brasileira, Brasília, DF, v. 39, n. 11, p. 1057-1064, nov. 2004.

BANCO MUNDIAL. Relatório sobre o Desenvolvimento Mundial de 2010: desenvolvimento e mudança climática. Visão geral antecipada. Washington, DC: Banco Mundial, 2010. 36 p.

BECK, U. World Risk Society. In: HENDRICKS, V. F; OLSEN, J. K. B.; PEDERSEN, S. A. (ed.). A companion to the philosophy of technology. New Jersey: Wiley-Blackwell, 2009. p. 495-499.

BEG, N. et al. Linkages between climate change and sustainable development. Climate Policy, [S. l.], v. 2, n. 2-3, p. 129-144, Sept. 2002.

BEHRENFELD, M. J. et al. Climate-driven trends in contemporary ocean productivity. Nature, London, n. 444, p. 752-755, Dec. 2006.

BELLARD, C. et al. Impacts of climate change on the future of biodiversity. Ecology Letters, [S. l.], n. 15, p. 365-377, Jan. 2012.

BERNAUER, T. Climate change politics. Annual Review of Political Science, [S.l.], v. 16, p. 421-448, May 2013.

BLANK, D. M. P. O contexto das mudanças climáticas e as suas vítimas. Mercator, Fortaleza, v. 14, n. 2, p. 157-172, maio/ago. 2015.

EAKIN, H.; LUERS, A. L. Assessing the vulnerability of social-environmental systems. Annual Review of Environment and Resources, [S. l.], v. 31, p. 365-394, Nov. 2006

EMBRAPA. Visão 2030: o futuro da agricultura brasileira. Brasília, DF: Embrapa, 2018. 212 p.

EULER, A. M. C. O acordo de Paris e o futuro do redd+ no Brasil. Cadernos Adenauer, v. XVII, n. 2, p. 85-104, 2016.

FAO. The state of food insecurity in the world 2012. Rome: FAO: WFP, 2012. 62 p.

FEAM. Plano de Energia e Mudanças Climáticas (PEMC). Plano de Energia e Mudanças Climáticas (PEMC), Belo Horizonte, 2015. Disponível em: http:/ / pemc.meioambiente.mg.gov.br/. Acesso em: 04. ago. 2020.

FEARNSIDE, P. Retrocessos sob o Presidente Bolsonaro: um desafio à sustentabilidade na Amazônia. Sustentabilidade International Science Journal, [S. l.], v. 1, n. 1, p. 38-52, abr./jun. 2019. 
FLEURY, L. C.; MIGUEL, J. C. H.; TADDEI, R. Mudanças climáticas, ciência e sociedade. Sociologias, Porto Alegre, v. 21, n. 51, p. 18-42, maio/ago. 2019. FUNDAÇÃO JOÃO PINHEIRO. Revisão do Plano Diretor do Município de Passos/MG: relatório informativo. Fundação João Pinheiro, Belo Horizonte, abr. 2019. Disponível em: http://novosite.fjp.mg.gov.br/wp-content/ uploads/2020/05/01-Relatório-preliminar-PD-PASSOS_ECONOMIA_ abr2020.pdf. Acesso em: 04 ago. 2020.

GHINI, R. et al. Análise de risco das mudanças climáticas globais sobre a sigatokanegra da bananeira no Brasil. Fitopatologia Brasileira, Brasília, DF, v. 32, n. 3, p. 197-204, maio/jun. 2007.

GIDDENS, A. The politics of climate change. Policy and politics, London, p. 1-19, 2015.

GONÇALVES, E. O padrão espacial da atividade inovadora brasileira: uma análise exploratória. Estudos Econômicos, São Paulo, v. 37, n. 2, p. 405-433, abr./jun. 2007.

HOWE, P. et al. Yale program on climate change communication. Yale Climate opinion Maps, Yale, 2016. Disponível em: https://climatecommunication.yale. edu/. Acesso em: 04 dez. 2020.

IBGE. Censo agropecuário 2017: resultados definitivos. IBGE, Rio de Janeiro, 2019. Disponível em: https://censoagro2017.ibge.gov.br/resultados-censoagro-2017.html. Acesso em: 04 ago. 2020.

IPCC. Climate Change 2007: the physical science basis. IPCC, Genebra, 2007. Disponível em: https://www.ipcc.ch/report/ar4/wg1/. Acesso em: 04 dez. 2020.

LIMA, M. A. Agropecuária brasileira e as mudanças climáticas globais: caracterização do problema, oportunidades e desafios. Cadernos de Ciência \& Tecnologia, Brasilia, DF, v. 19, n. 3, p. 451-472, set./dez. 2002.

MALCOLM, J. R.; MARKHAM, A. Global warming and terrestrial biodiversity decline. Gland: WWF, 2000. 34 p.

MARENGO, J. A; VALVERDE, M. C. Caracterização do clima no século XX e cenário de mudanças de clima para o Brasil no século XXI usando os modelos do IPCC-AR4. Revista Multiciência, Campinas, n. 8, p. 5-28, maio 2007.

MARTINS, S. et al. Mudanças climáticas e vulnerabilidade na agricultura: desafios para desenvolvimento de estratégias de mitigação e adaptação. Revista Brasileira de Ciências Ambientais, Rio de Janeiro, n. 17, p. 17-27, set. 2010. 
MIRANDA, S. et al. Apontamentos sobre mudanças climáticas na agricultura brasileira. Enciclopédia Biosfera, Goiânia, v. 15, n. 27, p. 95-196, 2018.

MMA. Plano Nacional de Adaptação à Mudança do Clima. Brasília, DF: MMA, 2015. 29 p.

PAULINO, V.; TEIXEIRA, E. Sustentabilidade de pastagens: manejo adequado como medida redutora da emissão de gases de efeito estufa. Pubvet, Maringá, v. 4, n. 24, p. 872-878, 2010.

PELlEGRINO, G. Q.; ASSAD, E. D.; MARIN, F. R. Mudanças climáticas globais e a agricultura no Brasil. Revista Multiciência, Campinas, n. 8, p. 139-162, maio 2007.

PIRES, M. et al. Percepção de produtores rurais em relação às mudanças climáticas e estratégias de adaptação no estado de Minas Gerais, Brasil. Revista de Ciências Agrarias, Lisboa, v. 37, n. 4, p. 431-440, 2014.

POUNDS, J. A. et al. Widespread amphibian extinctions from epidemic disease driven by global warming. Nature, London, n. 439, p. 161-167, Jan. 2006.

SEEG. Análise das Emissões Brasileiras de Gases de Efeito Estufa e suas implicações para as metas do Brasil: 1970-2018. São Paulo: SEEG: Observatório do Clima, 2019. 32 p.

VAN VUUREN, D. P. et al. A special issue on the RCPs. Climatic Change, [S. l.], n. 109, p. 1-4, Nov. 2011.

VINHA, M. B. et al. Impactos do uso indiscrimanado de agrotóxicos em frutas e hortaliças. Revista Brasileira de Agropecuária Sustentável, Viçosa, v. 1, n. 1, p. 102-107, jul. 2011. 
